\title{
New Editors, Features and Procedures
}

We are most pleased to announce several organizational and operational changes that were stimulated primarily by the need to keep pace with an increasing influx of manuscripts and recent dramatic developments in cytogenetics, somatic cell, and molecular genetics.

\section{New Editors}

We have added a new category of Editors, that of Executive Editors, who will work closely with the Editor-in-Chief. We are pleased that Dr. Thomas B. Shows, who has for several years served with distinction as the Associate Editor for the Gene Mapping Section, and Dr. Peter L. Pearson, who has served several terms on the Editorial Board have accepted these appointments. We are also very pleased that two members of the Editorial Board, Drs. Susan L. Naylor and Michelle M. LeBeau have agreed to join our board of Associate Editors. Sue's section encompasses gene mapping. Michelle's section encompasses the latter area in addition to cytogenetics and molecular genetics of cancer.

We are also very glad that Dr. Phyllis McAlpine has agreed to join our Board of Editors. Her expert advice and assistance in the ever more difficult and demanding task of maintaining an efficient and unambiguous system of gene nomenclature will be of great value to this Journal. Her and Tom Shows' enormous yet largely unrewarded efforts in developing and maintaining an International System of Human Gene Nomenclature has provided an immeasurable service to all human geneticists, and to gene mappers in particular.

Authors requiring provisional gene code names for new genes should contact Phyllis McAlpine (University of Manitoba, Department of Human Genetics, 250 Old Basic Sciences Building, 770 Bannatyne Ave., Winnipeg, Manitoba R3E OW3, Canada, Telephone: (204)788-6393, FAX: (204)786-8712, Bitnet address: genmap ${ }^{\circledR}$ uofmcc).

Manuscripts can be sent directly to the Associate or the Executive Editor of the appropriate Sections, as well as to the Editor-in-Chief.

Two Assistant Editors have also been added to the Editorial Office staff. This and the procedural changes discussed below should accelerate the publication of reports.

Section for gene mapping and cloning

The success of the Genetic Linkage Data section which we added a few years ago, and the large increase in the number of gene mapping and cloning reports we receive, which presents a problem in terms of space in the Journal, prompted the introduction of a new section: Gene Mapping and Cloning.

This section represents an experiment to publish mapping and cloning reports in a very compact and standard format (one or two printed pages) that would not only save considerable space but would make it easier and quicker for a reader to extract the essential information while at the same time insuring that all the minimal information and data required for evaluating the significance of the results are included. Guidelines for preparing such reports will be published in a forthcoming issue and in the Instructions to Authors section. In the interim authors can obtain this information directly form the appropriate Editors (see face page for addresses).

New Procedures 
We are continuing the process of the conversion to electronic processing of manuscripts. We thank authors who have assisted during the development phase by providing electronic versions of their manuscripts. Authors whose papers are accepted for publication will receive instructions on the procedure to be followed. First submissions should still be hard copies. We will continue to process hard copy versions from authors who do not have the appropriate electronic facilities. Electronic bulletin board

As announced in the previous issue, titles and abstract $\mathrm{s}$ of all papers published in 1989 in this Journal as well as all papers scheduled for publication, are posted on the Bulletin Board System (BBS) in collaboration with the American Society of Human Genetics. Instructions for free access to BBS, which also posts several other types of information of interest to investigators, were given in the previous issue. 